\title{
La vuelta por el siglo XIX. Una historia del mundo a través de los objetos $^{*}$
}

\author{
A Tour of the 19th Century. \\ A History of the World through Objects
}

\author{
Sylvain Venayre \\ Université Grenoble-Alpes, Francia. \\ sylvain.venayre@univ-grenoble-alpes.fr
}

Resumen: La historia del mundo en el siglo xIX supone un problema: ipor qué constituiría este siglo un capítulo coherente? Este trabajo responde a esa cuestión partiendo de la historia de los objetos. Cada objeto ofrece un medio de entrada a la historia del mundo, a los fenómenos de circulaciones y apropiaciones. Permite ver la cronología del establecimiento de redes en el mundo en el siglo XIX, así como las consecuencias, y también los límites de esta puesta en red. Saca a la luz los procesos de dominación. Estas circulaciones de objetos no son sólo imperiales: también dan testimonio de procesos de identidad en marcha, especialmente en la escala de las naciones. En las formas de co-

* Conferencia dictada en el Instituto Mora, Ciudad de México, 17 de agosto de 2016. Permítanme, antes que nada, agradecer muy cariñosamente a los organizadores de esta conferencia, en primer lugar, a Laura Suárez de la Torre por su invitación, y decirles cuán contento y orgulloso estoy de tomar la palabra aquí, en el Instituto Mora. Mi intervención estará dedicada a un proyecto sobre el que trabajo desde hace cinco años. Dicho proyecto es una historia del mundo en el siglo xIX, que dirijo junto con el historiador Pierre Singaravélou y será publicada el año próximo en las ediciones Fayard. Reúne a 90 historiadores, en su mayoría franceses. Una buena parte de esta conferencia proviene de los análisis de algunos de ellos en este libro.

Cómo cITAR: Venayre, S. (2019). La vuelta por el siglo xix. Una historia del mundo a través de los objetos. Secuencia (104), e1709. DoI: https://doi.org/10.18234/secuencia.v0i104.1709

cC 8 Esta obra está protegida bajo una Licencia Creative Commons Atribución-NoComercial 4.0 Internacional. 
lección del yo que ilustran los objetos reunidos en el magasin del siglo xIx, la habitación y el mundo mantienen una relación homotética, porque el mundo ha venido a la habitación como un ensamblaje global de cosas importadas y almacenadas.

Palabras clave: decimonónico; mundialización; industrialización; comunicación; siglo diecinueve; objeto.

Abstract: The history of the world in the 19th century is a problem: why would the 19th century be a coherent chapter? This paper answers this question through the history of objects. Each object offers a means of entering the history of the world, the phenomena of circulations and appropriations. This makes it possible to see the chronology of the establishment of networks in the19th century world, as well as the consequences, and limits of this networking. It brings the processes of domination to light. These circulations of objects are not only imperial: they also provide evidence of ongoing identity processes, especially on the scale of nations. In the forms of collection of the self-illustrated by the objects gathered in 19th century magasins, the room and the world maintain a homothetic relationship, because the world has come to the room as a global assembly of imported and stored things.

Key words: nineteenth-century; globalization; industrialization; communication; 19th century; object.

Fecha de recepción: 11 de octubre de 2016 Fecha de aceptación: 16 de febrero de 2017

\section{¿POR QUÉ EL SIGLO XIX?}

$E_{p}^{1}$ proyecto de una Historia del mundo en el siglo XIX supone de entrada un problema: ¿por qué constituiría el siglo xIX un capítulo coherente en la historia del mundo? Ciertamente el siglo es una unidad artificial, y los historiadores, en lugar de someterse a ella ciegamente, pueden sacar partido del artificio. La Historia del mundo en el siglo xV, dirigida por Patrick Boucheron, estaba fundada en esta evidencia. En lugar de usar el término "Renacimiento", 
que en el siglo xv no se refería más que a una pequeña parte del mundo (y aun más: a una pequeñísima parte de las elites sociales de esa pequeña parte del mundo), Boucheron y sus colaboradores habían elegido aislar un "siglo XV" que, en la época en cuestión, no tenía ningún sentido para absolutamente nadie en la superficie del globo. De esta forma, los autores de Historia del mundo en el siglo XV no esperaban privilegiar ningún punto de vista -y en particular ese punto de vista de las elites europeas, del que Jack Goody recordó hasta qué punto había orientado el discurso histórico mundial desde hacía varios siglos.

Una Historia del mundo en el siglo xıx plantea, sin embargo, un problema muy diferente. Fue precisamente en Europa donde, desde finales de la década de 1790, algunos autores se pusieron a hablar del "siglo XIX" por venir. El apelativo se difundió ampliamente en los títulos de gran cantidad de libros y aún más en periódicos, haciendo del "siglo xix" el primer "siglo" de la historia en ser nombrado por un número, en Europa y en América, y después en muchas otras partes del mundo.

No obstante, esta designación del "siglo XIX" vino acompañada de todo un imaginario de ruptura y modernidad. Al ser nombrado así, el "siglo xIx" apareció efectivamente como una nueva era de la historia humana, una nueva era pensada precisamente como el momento de una cierta adecuación del mundo a sí mismo, partiendo de las consecuencias de las ideologías, la industrialización, el progreso en los medios de transporte y de comunicación, el aumento de las migraciones internacionales $y$, por supuesto, las diferentes formas modernas de colonización.

Así pues, es muy tentador hacer del siglo xix el siglo de la mundialización, o de la globalización. Estos términos son ciertamente anacrónicos. Pero sabemos que en francés, el adjetivo mondial apareció en los años 1890 y ese surgimiento podría considerarse la culminación de una historia comenzada con el bautismo del "siglo xix", 100 años atrás. Así, en tanto que cronónimo, el "siglo xIx" sería la época que condujo a la llegada de la era mundial. Para los pesimistas, el siglo xix habría incluso preparado la oscura gloria de esa era: la de la primera guerra llamada "mundial", comenzada en ese año 1914 que a menudo señala, en los manuales de historia, el fin de la época designada como el "siglo XIX". Las representaciones que asocian de entrada al siglo XIX con el mundo son extremadamente actuantes hoy en día. No es casualidad que dos de los más célebres ensayos sobre la historia del mundo, los del británico Christopher Bayly y el alemán Jürgen Osterhammel, traten precisamente sobre el siglo xix. Para un número cada vez más elevado de historiadores, 
la historia del siglo xIx parece tener que escribirse, más que cualquier otra historia, en la escala del mundo entero.

Así, a pesar de que los historiadores franceses han participado bastante poco en la definición de la World history, de la Global history, o incluso en la historia "conectada" tan cara a Sanjay Subrahmanyam, es notable constatar que numerosos manuales de historia franceses se presentan desde hace tiempo como Historias del siglo XIX que abarcan al mundo entero. Es el caso, por ejemplo, de ese best-seller de la edición universitaria francesa que le debemos a Serge Berstein y Pierre Milza, y con el que desde hace 30 años se invita a los estudiantes que comienzan a iniciar sus lecturas. Hay otros similares pero al verlos de cerca nos podemos dar cuenta de que no son libros de historia del mundo, sino más bien un ensamblaje de capítulos, cada uno de los cuales aborda una región del mundo. En este género de libros, la parte más importante es la de Europa, en la que se distinguen muy particularmente cada uno de los grandes Estados de Europa occidental, comenzando por Gran Bretaña, Alemania, y, por supuesto, Francia. En cuanto al resto del mundo, si bien Estados Unidos de América, e incluso Japón están bien representados, no diríamos lo mismo de América del Sur, tratada muy someramente, o de África, reducida por lo general al papel de víctima del proceso de expansión colonial europea, por no mencionar a Oceanía. Esos libros no se pueden considerar tentativas de escritura de la historia del mundo. En ellos no existe ninguna voluntad de "provincializar Europa", retomando el título-programa del libro de Dipesh Chakrabarty. Casi no hay más rupturas que las impuestas por los acontecimientos políticos. Casi no se analiza la historia del establecimiento de redes en el mundo durante el siglo XIX, ni la historia, igualmente importante, de las resistencias e indiferencias con respecto a esta creación de redes. En el fondo, esa clase de libros no nos enseñan más sobre la historia del mundo en el siglo xIX que los primeros manuales aparecidos sobre el tema desde el comienzo del siglo xx -o incluso el proyecto de la Histoire du XIX siècle en el que trabajaba Jules Michelet la víspera de su muerte.

\section{APERTURA DEL MAGASIN}

¿Cómo escribir una historia del mundo en el siglo xix que se adapte a los retos de nuestra época -la cual inventó justamente las nociones de "mundialización" y de "globalización"?-. Conviene, claro está, describir y expli- 
car los grandes movimientos que han terminado afectando al planeta en su conjunto: industrialización y urbanización; expansiones religiosas y coloniales; cambio radical de los transportes y las comunicaciones; aumento de intercambios y migraciones; circulaciones aumentadas de las ideas, saberes y formas, etc. Al hacerlo, no obstante, es necesario desconfiar del modelo difusionista que, al repetir el discurso europeo del siglo xIX, condujo a pensar la historia del mundo como la reacción a un impulso venido de Europa (o de Occidente) y como el punto de partida de un movimiento de uniformización.

De la misma manera conviene conservar otras escalas que, para algunos fenómenos, son tan pertinentes como la escala del mundo. Los primeros subaltern studies mostraron que no se podían analizar las rebeliones campesinas en la India en función de las ideologías del progreso y la revolución que surgieron en Europa y en América a partir del final del siglo XVIII, sino que esos movimientos revolucionarios estaban a menudo fundados en representaciones del mundo que los europeos podrían calificar como reaccionarias, una palabra que, en la India de esa época, no habría tenido realmente ningún sentido. Pero tal como lo subraya Clément Thibaud en nuestro libro, la invocación de creencias religiosas, del milenarismo o de figuras paternalistas, así como el carácter local y limitado de las reivindicaciones, no constituyen argumentos suficientes para rebatir toda la dimensión revolucionaria de las rebeliones.

¿Cómo evitar, entonces, decretar arbitrariamente la unidad cronológica del siglo XIX? ¿Cómo sustraerse a la fuerza del modelo difusionista y tomar en cuenta las diferentes escalas que permiten comprender la complejidad del proceso de mundialización -y también de resistencia o indiferencia hacia ese proceso?-. Existen varias formas de hacerlo. Una de ellas nos pareció la creación, en el corazón mismo de nuestra Historia del mundo en el siglo XIX, de un magasin.

Como nos lo recuerda François-Xavier Fauvelle en nuestro libro, la palabra misma es testimonio de la circulación en gran escala. Magasin ingresó a la lengua francesa en el siglo xIV por medio del italiano magazzino, tomado a su vez del árabe makhzin, que significaba "depósito" o "despacho", es decir, el lugar de un poder que es a la vez el del almacenamiento de mercancías y el de la contabilidad e inventario. En árabe marroquí moderno, la palabra designa el "Palacio", en su sentido físico y político. El inglés magazine, tomado del francés, no conservó más que la acepción de depósito, almacenamiento de armas o municiones (al que una acepción aún más restringida del francés emplea para referirse, no a la armería, sino al cargador del revólver) antes de 
extenderlo al almacenamiento de información (que otra acepción del francés aplica para las reservas de un museo o de una biblioteca), y luego a su difusión en forma de publicaciones periódicas. Mientras que esta nueva palabra, magazine, ingresa al francés a finales del siglo XVIII, magasin termina refiriéndose, en el despunte del siglo XIX, a una "tienda", no sin que una acepción hoy envejecida designe a una prensa ilustrada, a la vez enciclopedia de las artes, almanaque y crónica de descubrimientos científicos y viajes (Le Magasin Pittoresque de Édouard Charton se publica así sin interrupción de 1833 a 1915). En todas sus formas, la palabra expresa en consecuencia la dualidad de un lugar que almacena y consigna, acomoda y muestra, presenta y registra.

¿Qué objetos podríamos encontrar en un "magasin del siglo XIX" así definido? ¿Cuáles nos parecerían hoy característicos de la época? En la medida en que tengo el tiempo limitado, quisiera concentrarme en dos de ellos para tratar de mostrarles, con la ayuda de estos ejemplos precisos, cómo desviarnos a través de los objetos, sus usos, las circulaciones que los afectaron, las significaciones que se les atribuyeron, puede permitirnos describir de otra forma la historia del mundo.

\section{EL RELOJ}

Consideremos el reloj, que Christophe Granger estudió justamente para la Historia del mundo en el siglo XIX, de donde retomo la demostración en su totalidad. A comienzos del siglo xIx, este objeto tiene ya una larga carrera marítima, científica y militar. Su uso nace de la búsqueda de la exactitud por parte de los intelectuales del siglo xVIII. El auge de la navegación científica exige, en efecto, la minuciosa determinación de las longitudes en el mar. A partir de 1714, las autoridades inglesas dotan al país de un Board of longitudes, destinado a estimular los estudios en la materia. En 1765, el relojero John Harrison se las arregla para desarrollar un reloj para marinos con sólo dos segundos de error después de 42 días de navegación. Después de 1830, los relojes se imponen en las actividades ordinarias de los barcos mercantes.

En tierra, en las ciudades, la posesión de relojes con mecanismos mucho más sencillos experimenta una implantación similar. En Londres, a finales del siglo XVIII, el objeto seduce a una clientela que supera en mucho a los únicos privilegiados por la fortuna. Marqueses y condes, pero también maestros cerrajeros, comerciantes de muebles o de pescado se encuentran en- 
tre la clientela de los relojeros. La organización de un mercado tiene como consecuencia, en el umbral del siglo xIx, la circulación de relojes a precios más atractivos y la popularización de su posesión. "Desde que tratamos a la relojería común como manufactura -señala Chaptal en 1819- el precio de los relojes y los péndulos ha bajado tanto que su uso se volvió general."

El optimismo de Chaptal es excesivo, pero muy ilustrativo de la conquista del público a la que se lanzan los relojeros. En Inglaterra, los centros de producción más importantes -Londres, Coventry, Liverpool- producen, en 1796, de 120000 a 190000 relojes, tantos que el gobierno emprende la instauración de un impuesto por cada reloj que se posea. Los valles suizos engordan la competencia. La producción se industrializa. Ciertas fábricas, como la de Elgin en Illinois, consiguen, al final del siglo, sacar 2000 relojes al día.

Por su parte, la red de vendedores se densifica: ya que ante todo dan muestra de coquetería, los relojes son vendidos en su mayor parte por joyeros, modistas, merceros y perfumeros. Frente a la demanda popular, los vendedores ambulantes y los prestamistas establecen, en la Inglaterra de 1810, un circuito lucrativo de relojes de contrabando baratos. La fabricación de relojes más rudimentarios contribuye también a hacer este objeto más accesible. En 1860, el relojero Roskopf, un alemán nacionalizado suizo, pone en circulación un reloj bautizado como Prolétaire, cuyo precio no rebasa el salario semanal de un obrero.

Pero, esencialmente, habría que situar la carrera de los relojes en el territorio entremezclado de la distinción y los nuevos significados de la hora. Si los "relojes de leontina", a menudo pequeños y redondos, alojados en el bolsillo del saco, la chaqueta o el chaleco, y amarrados por una cadena o una cinta, se convierten en un objeto familiar en Europa y en América, lo que permite entender el lugar que les corresponde en los modos de vida del siglo xIx es lo que se juega a través de ellos. El auge del reloj es contemporáneo de lo que Norbert Elias llama la "temporación" de las actividades humanas, es decir la costumbre de los hombres de marcar puntos de referencia temporales comunes para aquello que hacen. Esta armonización se establece alrededor de 1840, un poco antes en Inglaterra y en Francia, un poco más tarde en España o en Italia, en el seno de la administración de correos y transporte.

La voluntad de sincronizar los viajes en tren es la que impone la nueva preocupación por las horas y los minutos, más aún que los envíos del correo. Pronto el arraigo de las localidades a los distintos husos horarios aparece como un obstáculo para el funcionamiento de la red ferroviaria que se desa- 
rrolla. Para facilitar los viajes, se adquiere la costumbre de ajustar los relojes interiores de las estaciones a la hora de las capitales. Poco a poco, la uniformización de la hora conquista los relojes públicos y somete los relojes privados de los habitantes. Así, en 1835, en Londres, el astrónomo en jefe del reino toma la costumbre de encargar a su joven comisionado que recorra la ciudad con la ayuda de un cronómetro para dar la hora exacta, la misma para todos, a los relojeros de la ciudad y así sincronizar todos los relojes.

Ese mercado de la hora exacta, perpetuado hasta la primera guerra mundial, trae consigo una doble metamorfosis. Los relojes no sólo suscriben el nacimiento de un tiempo "artificial", independiente del curso del sol. Sobre todo marcan el advenimiento de una nueva concepción del tiempo que, en el seno de las burguesías europeas, valora la puntualidad, la intolerancia al retraso y a la contabilidad quisquillosa de las horas. El reloj, para las amas de casa, es el instrumento de una racionalización de la gestión del tiempo. Él acompaña a la costumbre de anotar, en las agendas y libretas que proliferan después de 1830, cómo se emplean las horas, repartidas y acomodadas.

Esta disciplina horaria inédita, cuyo medio y símbolo a la vez lo constituye el reloj, impregna al conjunto de las sociedades occidentales. El tiempo regulado de la hora se convierte en la unidad de la organización y la vigilancia de las escuelas, las prisiones, los cuarteles, los asilos y los talleres. E. P. Thompson pudo mostrar hasta qué punto el reloj había contribuido a imponer, en las fábricas inglesas del siglo xix, la nueva disciplina del trabajo industrial. Acompañó e hizo posible la puesta en marcha de un trabajo que, orientado antes hacia la tarea, en adelante adopta al tiempo y especialmente a la hora como la medida de su organización y retribución. Pero, al mismo ritmo, el reloj cuya posesión da el poder de vigilar el trabajo de los otros permite nuevos modos de dominación de la mano de obra. "Aparte del patrón y su hijo -cuenta un obrero inglés en 1827-nadie tenía reloj y no sabíamos qué hora era. Había un hombre con un reloj. Este le fue confiscado y quedó bajo la vigilancia del patrón, porque le había dicho la hora a sus colegas."

La influencia de este tiempo programado es engañosa. Por mucho tiempo, estuvo atrapada en una multitud de referencias temporales distintas, más porosas, las del día y la noche, las fiestas y las estaciones. Pero el reloj cumple su labor. Permite administrar el tiempo y administrar por el tiempo. Vuelve posible el sentido aumentado de la precisión horaria. Signo de autoridad, privativo del patrón, el contramaestre, el oficial o la institutriz, se encuentra también en el centro de un universo de nuevas prácticas. El reloj 
de oro, ofrecido como regalo de comunión de los padres o los amigos íntimos, ocupa su lugar en los ritos de la vida familiar. Tiene también su función, como alhaja, en la formación del gusto por los adornos. "El reloj, la tabaquera y el impertinente montado en oro -leemos en 1879- son las únicas joyas que debe permitirse un hombre educado." En cuanto a las mujeres, que únicamente usan el reloj de pulsera, se les invita a combinar el objeto con la variedad de sus atuendos.

Cargado con todas esas propiedades, el reloj se impone en el magasin del siglo XIX. Y es así como se mezcla con los encuentros entre mundos que en ese entonces se multiplican. Los relatos de exploradores y colonos abundan en descripciones del encuentro entre fascinado e impactado de los pueblos extraeuropeos con el utensilio. Las escenas suelen ser parecidas. Algunos, como el americano Audubon al hacerse invitar entre los indios de Norteamérica en 1840, cuentan el poder de seducción del objeto:

Extraje un bello reloj de mi pecho, diciéndole a la mujer que se hacía tarde y estaba cansado. Al ver esa joya, cuya riqueza no se le había escapado, pareció producir en su espíritu un efecto realmente eléctrico. Hubo que satisfacer su curiosidad mostrándosela enseguida. Saqué la cadena de oro que la detenía en mi cuello y se lo presenté. Se quedó en éxtasis frente a él, admiró su belleza, me preguntó cuánto costaba y pasó la cadena alrededor de su enorme cuello, exclamando que la posesión de un tesoro así la haría muy feliz.

Otros, médicos y oficiales, rivalizan al afirmar el efecto mágico del reloj sobre los pueblos supuestamente primitivos, su capacidad para despertar la fogosidad guerrera de las tribus africanas o, a la manera de sir Baker en las guerras con el hijo del rey Kamrasi en los confines del lago Victoria, para rescatar al aventurero occidental de las garras de sus carceleros. La escena se convierte en un lugar común. De hecho, el reloj autoriza la clasificación espontánea de los pueblos de la tierra. Acompaña y orienta el encuentro con mundos donde, para el gusto de los viajeros avezados en la magia del objeto, revela bruscamente su distancia con respecto a lo que estos consideran la encarnación de la "civilización". El francés Louis Noir afirma así en 1872:

El negro tiene una pasión extraña por los relojes; el reloj tiene algo misterioso que excita al punto más alto su curiosidad: lo toca estremeciéndose, observa los engranajes con un terror cómico, se queda en éxtasis ante las agujas. A 
veces se ve a 30 o 40 frente a las tiendas de relojes, la mirada en la vitrina, el pecho jadeante, las manos juntas, y siguiendo con ansiedad los movimientos del relojero, al que observan como a un brujo.

Como utensilio del progreso e indicador de la cultura occidental, a partir de 1870 el reloj se abre camino entre la buena sociedad urbana y después entre la población de los territorios surgidos del dominio imperial o, simplemente, de la influencia occidental. En Kenia, en India y en la península arábiga de la década de 1880, "la demanda de relojes baratos es considerable", de ser ciertos los informes británicos. Durante mucho tiempo, Beirut es el centro principal de aprovisionamiento. En 1902 importa más de nueve toneladas de relojes ingleses. Damasco se vuelve también un centro activo en la materia. Ahí no sólo se instalan los representantes de las principales firmas relojeras suizas, sino que la ciudad ve multiplicarse a los fabricantes locales de relojes, los sāātì.

Tal implantación no sólo procede de una apropiación de las costumbres occidentales. Tiene mucho que ver con la inmensa empresa de racionalización horaria a la cual se entregan, con motivo de la colonización, los administradores reformistas y los intelectuales musulmanes. La exigencia de exactitud en las vías ferroviarias, así como se manifiesta en Calcuta o Dar es Salaam, la nueva presencia de relojes en el espacio público de El Cairo, Alejandría y Estambul, la puesta en circulación de un idioma del tiempo que da lugar a la precupación por la precisión y el intercambio ordinario de referencias horarias, así como los debates sobre la reforma del calendario islámico y más aún sobre las horas de los rezos y las fechas de ramadán obraron para aclimatar el uso del reloj en mayor medida que la nueva disponibilidad de piezas de relojería.

La implantación del objeto en Japón es en parte similar. La apertura del país al comercio internacional en 1853 libera la posibilidad de un nuevo mercado. Hasta 1873, de todas maneras, este permanece en una estrechez extrema. Son necesarios el abandono del sistema tradicional de división del tiempo, la cultura de la exactitud que sostiene el desarrollo de las vías ferroviarias, su difusión a través de las escuelas y las fábricas, pero también la adopción en 1879 de una hora única en todo el país, transformaciones operadas bajo el impulso de los ingenieros británicos, para volver útil y necesario al reloj. La multiplicación de los negociantes, europeos y japoneses, que importan 200 000 piezas en 1890, más el desarrollo en el lugar de manufacturas de produc- 
ción y la puesta en circulación de relojes económicos permiten, en 1907, que un japonés entre diez posea el suyo.

Tal vez es en el movimiento que impone un poco por todas partes el sistema de las horas nacionales y después el de la hora mundial en 1911, que se mide de mejor manera el triunfo del reloj. Lo importante no es que Francia, en 1891, Alemania en 1893, Dinamarca en 1894 o España en 1900 adopten una "hora legal" donde se aloja la nacionalización de los puntos de referencia cotidianos, ni siquiera la discusión interminable, entre científica y política, que preside la elección del meridiano universal, el de Greenwich. Lo importante se encuentra en la preocupación común de señalar el tiempo del mundo, en la certeza de que existe un tiempo común que viene a marcar el ritmo de las actividades humanas en el conjunto del globo, del que el reloj se ha vuelto, en todas partes, el signo portátil.

\section{ROPA USADA}

Consideremos ahora otro tipo de objeto, que toca categorías sociales claramente menos favorecidas que aquellas que se benefician con la posesión de relojes: la ropa de segunda mano, precisamente estudiada por Manuel Charpy para nuestra Historia del mundo en el siglo xIx, y de la que tomo prestada igualmente toda su demostración. Los europeos del siglo xix le ponen atención de manera súbita durante la epidemia de cólera que, partiendo del Ganges en 1817, alcanza a Europa en 1832, tras haber pasado por el oriente de África y Asia Menor, mientras que otra cepa se propaga por la vía de las caravanas de peregrinos a La Meca. Entonces las miradas voltean hacia las vestimentas que circulan por el mundo, en particular las ropas de segunda mano, las que llaman fripes, consideradas a partir de entonces como desperdicios cargados de miasmas. En Francia, las autoridades prohíben desde 1831 la importación de "todos los efectos de vestir viejos o incluso simplemente tolerados que constituyen el comercio de trapería". El vínculo entre epidemia y ropa vieja queda subrayado por los relatos de los episodios de contagio: en 1819, ¿acaso los marinos ingleses llegados de Calcuta no diezmaron a los habitantes de Isle de France (hoy isla Mauricio) al venderles harapos? Las mismas inquietudes y las mismas medidas para el cólera en la década de 1880. Mientras en París los médicos observan una concentración de los decesos en el barrio del Temple, el mayor mercado mundial de ropa usada, las prohibiciones a la importación de 
ropa de ocasión se multiplican en toda Europa, de Austria-Hungría a Rumanía, pasando por el reino de los Países Bajos. En 1889, las autoridades danesas establecen la lista de países prohibidos para la importación de ropa usada en el reino: Marsella, los puertos de Sicilia, Egipto, Tonkín y la Cochinchina, las Indias neerlandesas y orientales, el Mar Rojo, Brasil, Cuba, Haití y Puerto Rico...

Aquellas medidas son en vano, pues la ropa en general está desinfectada. Sin embargo, nos interesan en tanto dan testimonios del carácter transnacional del comercio de la ropa usada. Nos equivocaríamos al considerarlo como arcaico. En realidad está muy estructurado y en gran escala. $\mathrm{Su}$ aprovisionamiento no es azaroso: los ropavejeros, que emplean a veces a más de una decena de personas, compran en masa a las administraciones, en particular a los ejércitos ingleses y franceses que dan de baja centenares de miles de piezas, pero también al Correo, a los pensionados, a las arquidiócesis, etc. A estos uniformes, a menudo reteñidos y ajustados se añade el flujo de los "trapos burgueses" recolectados por los ropavejeros y seleccionados en talleres y, finalmente, después de 1850, los trajes defectuosos de la naciente confección industrial.

En ese mercado dominan Londres y París, las dos capitales de la moda. Los mercados tradicionales dejan su lugar para actividades concentradas. En París, el Temple se convierte en un centro neurálgico, sobre todo porque bajo el segundo imperio, la municipalidad manda construir un mercado especializado que alberga a más de 1500 ropavejeros, ofreciendo 2000 lugares el nuevo mercado de 1865. En Londres, centenares de tiendas se concentran en Pettitcoat Lane y en la década de 1840, los comerciantes crean ahí el Old Clothes Exchange que cuenta con 90 lugares grandes. Nueva York -alrededor de las calles Baxter y Chatham-, Boston y Filadelfia son también centros donde se vuelve a barajar la ropa usada de todo el mundo. París y Londres importan prendas de segunda mano de toda Europa: durante el año de 1859, el Temple compra 71 toneladas en el Reino de Cerdeña, 22 toneladas en Inglaterra, 19 toneladas en Bélgica, cinco toneladas en Argelia. Seleccionada y a veces modificada, se reexporta. El Temple la reenvía a los ropavejeros de toda Francia, en tiendas o ferias, de la Bretaña al Delfinado. El Old Clothes Exchange exporta al País de Gales, Escocia y sobre todo Irlanda. De Nueva York salen las pacas hacia el oeste y el sur del país. Las exportaciones son también internacionales. En Francia, las aduanas crean en 1834 la rúbrica "ropa vieja o sufragada". Para el Temple, los países europeos absorben $60 \%$ de las exportaciones, es decir 1200 toneladas a finales de la década de 1860, 
de las cuales la mayor parte va hacia la Zollverein (187 t), el Reino de Cerdeña (163t), Bélgica (116 t), Suiza (104t).

Muy a menudo, y desde la década de 1820 , esta ropa usada compactada en pacas cúbicas de $130 \mathrm{~kg}$ cruza los límites de Europa. Un contemporáneo señala en 1855 que las tiendas del Temple "envían los sobrantes de sus guardarropas al Congo, Senegal o las Indias Occidentales, donde hacen las delicias de los reyes negros y los petimetres de Santo Domingo o Barbados". En realidad, exportan ante todo a Rusia, Estados Unidos, las Antillas y las jóvenes naciones sudamericanas que visten a sus nuevos ejércitos con uniformes reformados -más de 800 toneladas de uniformes en 1859 van hacia las Antillas y Brasil. En la década de 1860, Alexis de Gabriao observa en la joven república de Ecuador "soldados indígenas a quienes les encasquetaron viejos uniformes de la artillería francesa" y Brasil contabiliza entonces sus importaciones de ropa usada, a tal punto son importantes, en 3900000 francos, tanto como las de calzado. Estos uniformes, modificados, se compran también para la población civil tanto europea como indígena.

África del Norte y las costas africanas aparecen como nuevos mercados en la década de 1830, especialmente Argelia que, con 156 toneladas importadas en 1860, se convierte en un espacio de tránsito hacia el Magreb y el África subsahariana, al limitar las autoridades metropolitanas el comercio de uniformes por miedo a los desvíos. En las costas africanas, la ropa usada europea está por todas partes, de Saint-Louis de Senegal a la Bahía Delagoa, pasando por Libreville.

Estos circuitos internacionales se desarrollan con mucha mayor facilidad en tanto que retoman y conectan circuitos preexistentes. Es, por una parte, la trama de las ferias, mercados y tiendas de ropa usada de Lima a Pekín, pasando por Túnez. Son, por otra parte, las redes de exportación de confecciones que existían desde el siglo xviI. La confección naciente en París, Londres y Nueva York se desarrolla exportando sus modelos rezagados a final de temporada hacia el hemisferio sur, en contraestación, en particular hacia América del Sur, lo que evita liquidarlos en Europa. También son masivas las exportaciones hacia las Indias y las costas occidentales de África donde, se felicita el confeccionista Lémann en 1857, "hasta los salvajes buscan nuestra ropa". Zonas de exportación de prendas de ocasión y confeccionadas se confunden entonces, a tal punto se parecen a los ojos de los consumidores. La ampliación de este comercio a escala mundial es acelerada por la semiconfección, que permite a los fabricantes alemanes mandar a cortar sus piezas en 
Inglaterra, donde la mano de obra es más barata, antes de que sean ensambladas a la medida de los clientes por todo el mundo. Esta ropa en piezas separadas paga muy pocos impuestos en las aduanas, al igual que la ropa usada, asimilada al comercio de los desechos industriales.

Si bien Londres y París dominan este mercado, conviene subrayar que gran cantidad de circuitos se les escapan. Es el caso, por ejemplo, de Tartaria donde, señala el Padre Huc en 1845 ante los puestos de ropavejeros, "no se experimenta la menor repugnancia por servirse de la ropa de otros", en ese caso chinos. Lo mismo en Manchuria donde, en la década de 1870, enormes pacas de ropas de segunda mano chinas circulan a través del mar amarillo entre China y Corea, o con los ropavejeros del zoco de Túnez que venden sobre todo albornoces, haiks y feces de ocasión.

Pero por lo general estos comercios entremezclaban mundos diferentes. Eso es lo que observa desde 1806 John Barrow en Lima, a donde la ropa usada llega con los balleneros que vienen del Cabo de Buena Esperanza. Un siglo después, en Bukoba, sobre las riveras del lago Victoria, los ropavejeros-mayoristas de Berlín intercambian ropa usada por pieles con detallistas indios que a su vez se los venden a vendedores ambulantes swahilis y a la población. Al mismo tiempo, en Estambul, mayoristas franceses aprovisionan a los ropavejeros armenios que enseguida se internan en los campos de Anatolia.

Esta historia es también la de una dominación política, económica y cultural sobre los cuerpos. El trueque de prendas viejas contra productos locales, incluso esclavos, es práctica corriente desde el siglo XVIII, desde las Indias orientales hasta las costas de África oriental y occidental. Misioneros y colonos distribuyen ropa usada, tanto para seducir como para someter los cuerpos, convirtiéndose estas ropas en banderas plantadas en los territorios conquistados. El arzobispo, autor de À l'assaut des pays nègres (1884) le quita a esto el misterio cuando manda a comprar "trajes de senadores o de ministros" en el Temple, para atraerse la buena voluntad del rey Mtésa en Uganda, estrategia que ya había experimentado en una misión en América del Norte, al distribuir a los jefes convertidos trajes suizos de parroquia. Esta sumisión se vuelve a menudo más violenta aún por la imposición del uso de ropas occidentales por parte de las autoridades religiosas y políticas, no sólo a los soldados sino también al personal administrativo y doméstico. Imaginamos entonces que visten los trapos de sus amos: en realidad se visten de ropa usada.

Si bien se felicitan de la civilización de estos cuerpos ganados al pudor, a lo largo de los relatos de viaje se burlan de esos "salvajes" civiles y soldados 
que no dominan ni las buenas maneras ni los códigos de la vestimenta como si fueran reyes. En África, una descripción parecida se convierte en un lugar común. El relato de Stanley, reproducido sin parar, trata de los atuendos estrafalarios de los jefes locales a lo largo del río Congo, como ese jefe en Vivi que portaba "una librea azul de criado, un gorro frigio en tejido multicolor y un calzón de tono chillón”.

En una primera época, estos juegos con los códigos de la vestimenta no preocupan ni a las administraciones, ni a los exploradores, pues los jefes cargados de oropeles como jefes de opereta parecen estar adaptándose torpemente a la civilización europea. Pero notamos una difusión de estas prácticas entre la población. Domeny de Rienzi señala desde 1836: "Antes, los tahitianos estaban desnudos o casi desnudos; hoy están celosos de nuestros trajes e incluso de nuestras botas y nuestros sombreros [...]. Es verdad que los misioneros, queriendo extirpar el tatuaje y volverlos cada vez más tributarios del comercio inglés, les recomendaron vivamente cubrirse el cuerpo. [...] Las tiendas del Temple o del mercado de Saint Jacques se transportaron a Tahití.”

Tanto en Oceanía como en África, el consumo de ropa usada por los civiles es antiguo pero su difusión lo vuelve visible a partir de la década de 1880. Stanley sueña mercados en África para la "ropa de ocasión europea, tal como se lleva en White-Chapel", señalando que ha "encontrado por millares niños negros del África que no se sienten en falta si utilizan los trajes viejos de los pálidos niños europeos, sino que por el contrario, hacen muchos esfuerzos para reunir con qué comprar estos trajes”. El rey vestido de manera ridícula provoca risa, pero los criados y los pequeños comerciantes que se visten elegantemente molestan cada vez más.

La práctica, difícil de controlar, se vuelve incluso inquietante, a tal punto que cuestiona el sistema colonial. El teniente belga De Witte lo señala en 1913:

Los indígenas de la región de Brazzaville se visten demasiado y, el domingo, aquellos que poseen varios pantalones, varios gabanes, se ponen estas ropas unas encima de las otras, para desplegar sus riquezas. Muchos se jactan de seguir la moda parisina y, sabedores de que antes los europeos bromeaban sobre la pasión de los negros por los sombreros de copa, tan poco apropiados para el clima tropical y a veces como complemento cómico de un traje más que somero, la mayoría de ellos ha renunciado a usarlos y hoy enarbolan elegantes panamás. 
Pronto este vuelco de las jerarquías de la elegancia se ve como peligroso. Las administraciones coloniales se ponen a vigilar los usos de la ropa de segunda mano, independientemente de que ciertas oposiciones al colonialismo pasen por el rechazo a la vestimenta occidental -con el movimiento swadeshi en la India, por ejemplo- o por una elegancia subversiva en el Congo. Relaciones de dominación, rechazo a las jerarquías y aculturaciones complejas: la ropa usada se encuentra durante el siglo xIx muy en el corazón de la mundialización vestimentaria y de sus implicaciones políticas, sociales y culturales.

\section{OTRA HISTORIA DEL MUNDO}

Un magasin del siglo xIX contendría muchos otros objetos, además de relojes y ropa usada. En nuestro libro hemos almacenado y mostrado carbón, caucho y marfil, opio, fusiles y quinina, biblias y libros islámicos, corsés y té, archivos y mapas, sillones, bibelots y espejos, daguerrotipos y estampas, alambre de púas e incluso tatuajes y animales. Cada uno de estos objetos ofrece un medio de entrada original a la historia del mundo, gracias al estudio de estos fenómenos de circulaciones y apropiaciones que renuevan útilmente, hoy en día, la gran división que la historiografía, especialmente la francesa, había establecido hace 40 años entre el orden de las prácticas y el de las representaciones. Si se emprende desde ese punto de vista, la historia de los objetos está llena de enseñanzas. Para concluir esta conferencia, escogeré cuatro de ellas.

En primer lugar, la historia de los objetos permite ver perfectamente la cronología del establecimiento de redes en el mundo en el siglo XIX, así como las consecuencias, pero también los límites, de esta puesta en red. Es verdad en lo tocante a la circulación de los relojes y la ropa usada. Pero también es verdad en relación con numerosos objetos. De haber tenido tiempo, habría podido mostrar cómo la historia del corsé nos conduce de la invención de nuevas normas para el cuerpo de las mujeres occidentales, hasta esta gran pesca de ballena por todos los océanos del mundo, cuyo carácter viril celebró Melville. También habría podido mostrar cómo la historia de la bicicleta nos conduce desde las primeras carreras organizadas por los diarios en la Europa de la década de 1870 hasta el "escándalo de las manos cortadas" en el Congo de la década de 1900, cuando se vio que la demanda de caucho para fabricar especialmente los neumáticos de las bicicletas impuso el establecimiento de un muy pesado 
aparato de coerción en la cuenca del Congo con el fin de aumentar los rendimientos del cultivo de los árboles de caucho.

Ya que, y es la segunda enseñanza de esta historia, el estudio de los objetos saca a la luz los procesos de dominación que acompañaron en el siglo XIX, la puesta en red del mundo. El caucho no es más que un ejemplo, obtenido de la historia de las materias primas. El carbón podría constituir un segundo ejemplo, por otra parte paradójico ya que se trata aquí menos de la depredación de mundos lejanos que de la escenificación de la superioridad europea. En Londres, en 1851, la presencia de un enorme bloque de carbón de 24 toneladas a la entrada de la exposición universal, junto a la estatua de Ricardo Corazón de León, significaba en efecto que Gran Bretaña había sido elegida por la Providencia: ipor qué habría dado Dios tantas minas de carbón a los ingleses y tan fácilmente utilizables si no era para permitirles dominar el mundo?

Muchas otras circulaciones se pueden interpretar aquí. Las del opio, organizadas por las compañías británicas entre India y China, tuvieron grandes consecuencias. Desde el punto de vista político, fueron las dos guerras llamadas "del opio", gracias a las cuales los europeos y los estadunidenses se establecieron en China. Pero hubo otros aspectos, a menudo desapercibidos: en Shanghái, los fumaderos de opio fueron los primeros edificios iluminados con electricidad. Podemos seguir de la misma manera la historia de la quinina o la del fusil, dos objetos que desempeñaron un papel esencial en el proceso de colonización europeo del siglo XIX. Podemos analizar igualmente las circulaciones de los libros religiosos, trátese de la Biblia a partir de la adhesión de los protestantes a la empresa de los misioneros a finales del siglo XVIII, o de los libros islámicos. El estudio de las circulaciones de los libros islámicos es además particularmente interesante: nos damos cuenta de que se trata esencialmente de poesía, de derecho musulmán o devoción sufí -y muy rara vez de Coranes-. Para la inmensa mayoría de los musulmanes en esa época, por lo demás analfabetas, el Corán en tanto que objeto no era más que un prontuario para apoyar los textos aprendidos de memoria y casi siempre acompañados de glosas y comentarios. Para decirlo como Catherine Mayeur-Jaouen, el Corán era menos un objeto que una salmodia. Hacer de él un objeto sería incluso plantar en el siglo XIX un imaginario wahhabita contemporáneo anacrónico. Ciertamente el mundo del siglo XIX no se puede reducir a una suma de objetos.

Uno de los objetos que manifiesta mejor los procesos de dominación imperiales en el siglo XIX es tal vez el marfil, que ocasionó los grandes exterminios 
de elefantes, sobre todo en África del este. Se necesitaba para fabricar otros objetos, todos también característicos del siglo: bolas de billar, mangos elaborados para los cuchillos, bellos peines $-y$, sobre todo, teclas de piano, en una época en que la práctica musical centrada en el piano participaba en la redefinición de la feminidad angloamericana-. Imaginemos que la producción de pianos pasó de 2000 por año a comienzos del siglo xIx a 500000 por año al final del siglo -y que eso alcanzó a muchos otros lugares aparte de Londres, París o Viena: en 1880, la enseñanza del piano se había vuelto obligatoria en las escuelas normales de Japón-. Aquello tuvo grandes consecuencias. En África austral, por ejemplo, aun cuando la región no fue nunca un productor importante, el comercio del marfil fue decisivo en la génesis del reino zulu. La penetración de los comerciantes de marfil europeos en la región de Phongolo-Mzimkhulu condujo en efecto a transformar la organización social y política de las jefaturas, las cuales reunían entonces bandas de jóvenes para cazar los elefantes y controlar las rutas comerciales. Estas bandas se estructuraron progresivamente como ejércitos, los cuales constituyeron la estructura de las grandes entidades políticas de la región, comenzando por el Estado zulu del célebre Shaka.

En África del este, de donde provenía la mayor parte del marfil, fue aún peor. La importancia de las compras de marfil condujo a multiplicar el comercio de armas de fuego de contrabando (a medida que los fusiles se perfeccionaban en Europa y América, los antiguos modelos eran revendidos en África y Asia). Esto condujo también a aumentar el tráfico de esclavos: eran además los mismos circuitos los que organizaban el comercio de marfil y el de esclavos. La despotización de las sociedades africanas está ligada así al comercio del marfil, el cual proporcionó al mismo tiempo, junto con la ideología antiesclavista, una justificación moral a la colonización europea. Para decirlo como Henri Médard, quien ha trabajado sobre esta cuestión para nuestro libro, el gusto burgués por el piano, acompañado del enriquecimiento y el aumento del tamaño de las clases acomodadas en la Europa del siglo XIX, condujo en el África al surgimiento de una economía de la depredación caracterizada por la difusión de las armas de fuego y el comercio de trata, que liga de manera indisociable marfil y esclavitud. Abrió la vía a la conquista colonial de sociedades africanas debilitadas, fracturadas por sus tiranos locales. Para decirlo de otra manera, el gusto europeo por Beethoven y Brahms fue una de las vías que condujo a la colonización.

Estas circulaciones de objetos $-y$ esta es la tercera enseñanza que podemos obtener de esta historia-, no son sólo circulaciones imperiales: tam- 
bién dan testimonio de procesos de identidad en marcha durante el siglo XIX, especialmente en la escala de las naciones. La historia del té constituye una ilustración perfecta de ella, pues el comercio del té con India y después con China condujo de manera progresiva a los ingleses a hacer del té una bebida nacional, acompañada de todo un conjunto de nuevos rituales, entre ellos el five o'clock tea (donde volvemos a encontrar la importancia del reloj), que aparece en la década de 1840 . Tal vez este toca al principio a la aristocracia: se dice que el five o'clock tea habría sido inventado por la duquesa de Bedford. Pero la práctica se extendió rápidamente a las clases medias y populares, tanto por imitación de la aristocracia como por la preocupación moral de luchar contra la supuesta intemperancia de las clases populares del reino.

Otro objeto manifiesta muy bien igualmente, en otro lugar del mundo, la historia de las construcciones identitarias: el fez. Es este sombrero de fieltro rojo, más o menos suave y a menudo adornado de una borla de seda oscura. Combinado con uniformes a la europea, fue progresivamente impuesto a los hombres de Estado del Imperio Otomano por toda una serie de recomendaciones, decretos y leyes suntuarias: en Estambul en 1796, y después en 1829, en Túnez a partir de 1831, etc. A partir de la década de 1820, se convirtió en el emblema de la reforma de los ejércitos otomanos, reforma por excelencia que a su vez condicionó la reorganización de la fiscalidad, la administración y por lo tanto de un cierto orden social. Ahora bien, así como lo establece muy bien M'hamed Oualdi, que dedica a este objeto un artículo en nuestro libro, el fez es reinventado como símbolo de una identidad imperial islámica precisamente en el momento en que su producción es cada vez menos controlada por los manufactureros otomanos y de manera creciente por manufactureros europeos -en este caso italianos, franceses y sobre todo austriacos, siendo gran parte de esta producción pura y simple falsificación de las marcas tunecinas-. La razón es por supuesto la industrialización de Europa y su inserción en una economía cada vez más global, de la cual es testimonio también el hecho de que a finales del siglo xix, la lana que sirve para la fabricación de los feces europeos no viene ya de España sino de Australia.

Las primeras décadas del siglo $\mathrm{xx}$ vieron desaparecer progresivamente la significación que el fez había adquirido a comienzos del siglo XIX, al distanciarse algunos de ese símbolo del poder imperial, a pesar de que los poderes coloniales, que buscaban neutralizar la antigua fuerza simbólica del fez, buscaron folclorizarlo. Aun cuando ciertos líderes nacionalistas lo movilizaron en el marco de la lucha por la independencia, desde Marruecos hasta las In- 
dias, el fez dejó de representar los mismos valores que antes. Este ejemplo nos permite también comprender cómo la historia de los objetos permite a veces resolver el problema de la cronología, por el que comencé. Si para el mundo otomano el siglo xix fue el siglo del fez, entonces comenzó en las décadas de 1780-1790 para extenderse hasta las de 1910-1930 -e incluso, en ciertos lugares, hasta los años de 1950.

La cuarta enseñanza que podemos obtener de una historia global de los objetos en el siglo xix me servirá de conclusión. En nuestro libro, François-Xavier Fauvelle señala que es sorprendente la multiplicidad de formas de colección del yo que ilustran los objetos reunidos en el "magasin del siglo xIx". La estampa, el daguerrotipo, el bibelot, el sillón, nos hablan menos del mundo que de nosotros. El daguerrotipo sirvió de entrada a una empresa de duplicación de la apariencia física del individuo. La edad de oro del bibelot, del que es testimonio la invención de la estantería con vitrina en la década de 1830, significó en principio la puesta en escena del coleccionista, ese individuo cuya sola acción dio sentido al conjunto de objetos reunidos. Para decirlo como François-Xavier Fauvelle, hay algo perturbador en esta reunión -turbación que es necesario interrogar por lo que revela de la relación con el yo y el mundo en la que reconocemos un aire de familia con nuestro presente-. No es el deslumbramiento del gabinete de curiosidades, colección de muestras traídas para dar fe de la diversidad de la creación. Es la disponibilidad de la cosa para su utilización; todo, en el magasin del siglo xIX es consumible o tiene por lo menos un destino; todo es ahí, como lo dice más precisamente la lengua inglesa, una "comodidad". Opio, quinina, sofá, reloj, fotografía, bibelot, ropa: todos esos objetos expresan una relación con el mundo que se dice en términos de ergonomía, es decir, de acomodo dialéctico de la materia "en sî" y de la conciencia de sí.

Serge Gruzinski decía que el siglo XVI se planteó por primera vez la pregunta “Qué hora es allí?”, aprehendiendo así la totalidad del mundo y la contemporaneidad de sus partes. Por su parte, François-Xavier Fauvelle subraya que los hombres y las mujeres del siglo xIX experimentaban otra cosa, del orden de las sensibilidades. En 1794, el viajero de Xavier de Maistre daba la vuelta a su habitación en 42 días. En 1872, el de Jules Verne efectuaba la vuelta al mundo en 80 días, es decir, apenas menos del doble -y en 1900 unos periodistas batieron el record de Philéas Fogg, por cuenta de sus respectivos periódicos, efectuando la vuelta al mundo en 63 días. La comparación del Voyage autour de ma chambre de Xavier de Maistre con el Le tour du monde en 
quatre-vingts jours de Jules Verne es menos insólita de lo que se podría pensar. La habitación y el mundo mantienen una relación homotética. No sólo porque el mundo ha venido a la habitación como un ensamblaje "global" de cosas importadas y almacenadas, sino porque estos dos espacios se han convertido en los ámbitos por excelencia de la consumación del yo, ese héroe verdadero que se construye y se ilustra tanto en la aventura solitaria de la introspección como en la de la exploración, que requiere columnas de cargadores y turbinas de vapor, es decir, explotación de mano de obra -esta "condición negra" (para retomar la expresión de Achille Mbembe) que se ha convertido en el orden del mundo- y artefactos. No que la habitación y el mundo no se perciban aquí sino bajo la especie del interior burgués del mundo occidental y de los imperios coloniales, escribe François-Xavier Fauvelle, sino que finalmente todo ello supone la copresencia, si se quiere "utilitarista", del material de origen y del bien manufacturado vendido en tiendas, del trabajador forzado del Congo y el comprador de París o de Filadelfia, que separa una cadena de operaciones y de transportes cuya descripción e interpretación deben ser el primer tema de los historiadores que, hoy en día, quieren hacer la historia del mundo. 